\title{
Ellagitannins with a glucopyranose core have higher affinity to proteins than acyclic ellagitannins by isothermal titration calorimetry
}

Article

Accepted Version

Karonen, M., Oraviita, M., Mueller-Harvey, I., Salminen, J.-P. and Green, R. J. (2019) Ellagitannins with a glucopyranose core have higher affinity to proteins than acyclic ellagitannins by isothermal titration calorimetry. Journal of Agricultural and Food Chemistry, 67 (46). pp. 12730-12740. ISSN 0021-8561 doi: https://doi.org/10.1021/acs.jafc.9b04353 Available at https://centaur.reading.ac.uk/87023/

It is advisable to refer to the publisher's version if you intend to cite from the work. See Guidance on citing.

To link to this article DOI: http://dx.doi.org/10.1021/acs.jafc.9b04353

Publisher: American Chemical Society

All outputs in CentAUR are protected by Intellectual Property Rights law, including copyright law. Copyright and IPR is retained by the creators or other copyright holders. Terms and conditions for use of this material are defined in the End User Agreement. 


\section{www.reading.ac.uk/centaur}

\section{CentAUR}

Central Archive at the University of Reading

Reading's research outputs online 
This document is confidential and is proprietary to the American Chemical Society and its authors. Do not copy or disclose without written permission. If you have received this item in error, notify the sender and delete all copies.

\section{Ellagitannins with a Glucopyranose Core Have Higher Affinity to Proteins than Acyclic Ellagitannins by Isothermal Titration Calorimetry}

\begin{tabular}{|r|l|}
\hline Journal: & Journal of Agricultural and Food Chemistry \\
\hline Manuscript ID & jf-2019-04353x.R2 \\
\hline Manuscript Type: & Article \\
\hline Date Submitted by the & $\mathrm{n} / \mathrm{a}$ \\
\hline Complete List of Authors: & $\begin{array}{l}\text { Karonen, Maarit; Turun Yliopisto, Department of Chemistry } \\
\text { Oraviita, Marianne; Turun Yliopisto, Department of Chemistry } \\
\text { Mueller-Harvey, Irene; University of Reading, Department of Agriculture } \\
\text { Salminen, Juha-Pekka; Turun Yliopisto, Department of Chemistry } \\
\text { Green, Rebecca; University of Reading, School of Pharmacy }\end{array}$ \\
\hline
\end{tabular}

\section{SCHOLARONE ${ }^{m}$ Manuscripts}




\section{Ellagitannins with a Glucopyranose Core Have Higher Affinity to Proteins than Acyclic Ellagitannins by Isothermal Titration Calorimetry}

Maarit Karonen ${ }^{*} \dagger$, Marianne Oraviita ${ }^{\dagger}$, Irene Mueller-Harvey ${ }^{\ddagger}$, Juha-Pekka Salminen ${ }^{\dagger}$, and Rebecca J. Green ${ }^{*}, \S$

${ }^{\dagger}$ Natural Chemistry Research Group, Department of Chemistry, University of Turku, Vatselankatu 2, Turun Yliopisto, Turku FI-20014, Finland

¥School of Agriculture, Policy and Development, University of Reading, Earley Gate, P.O. Box 236, Reading RG6 6AT, United Kingdom

$\$$ School of Chemistry, Food and Pharmacy, University of Reading, Whiteknights, P.O. Box 224, Reading RG6 6AP, United Kingdom

* (M.K.) Tel: + 35829450 3179. E-mail: maarit.karonen@utu.fi.; (R.J.G) Phone: +44 118378 8446. Email: rebecca.green@reading.ac.uk. 


\section{ABSTRACT:}

2 The thermodynamics of the interactions of different ellagitannins with two proteins, namely bovine serum

3 albumin (BSA) and gelatin, were studied by isothermal titration calorimetry. Twelve individual ellagitannins,

4 including different monomers, dimers and a trimer, were used. The studies showed that several structural

5 features affected the interaction between the ellagitannin and the protein. The interactions of ellagitannins with

6 proteins were stronger with gelatin than with BSA. The ellagitannin-gelatin interactions contained both the

7 primary stronger and the secondary weaker binding sites. The ellagitannin-BSA interactions showed very weak

8 secondary interactions. The ellagitannins with a glucopyranose core had stronger interaction than $C$-glycosidic

9 ellagitannins with both proteins. In addition, the observed enthalpy change increased as the degree of

10 oligomerization increased. The stronger interactions were also observed with free galloyl groups in the

11 ellagitannin structure and with higher molecular flexibility. Other smaller structural features did not show any

12 overall trend.

13

14 KEYWORDS: binding, bovine serum albumin, ellagitannin, gelatin, isothermal titration calorimetry, 15 thermodynamics 


\section{INTRODUCTION}

Tannins are plant secondary metabolites, which could also be called plant specialized metabolites ${ }^{1,2}$. Plants produce them in their tissues to protect themselves against, for example pathogens and insect herbivores. Tannins are polyphenols that have the ability to bind and precipitate proteins and they can be divided into three groups: hydrolysable tannins, proanthocyanidins (syn. condensed tannins) and phlorotannins. Hydrolyzable tannins are further divided into simple gallic acid derivatives, gallotannins and ellagitannins. Ellagitannins (ETs) are a structurally complex group and individual structures vary from simple hexahydroxydiphenoyl (HHDP) esters to high oligomers with both varying degree of oligomerization and types of bonds between the monomers. ${ }^{3,4}$ ETs have been stated as the most promising tannin class with potent biological activities, such as antimicrobial, antioxidant and antiparasitic activities., ${ }^{3,5-8}$

Some dietary tannins can have several beneficial effects in animal nutrition and health, for example, through enabling a better utilization of feed proteins, generating anthelmintic effects against gastrointestinal nematodes, and lowering nitrogenous and methane emissions. ${ }^{8-13}$ The interactions between tannins and proteins plays an important role in these bioactivities observed. Tannins may bind dietary proteins and thus can reduce the degradation of these proteins in the rumen and they may also enhance the amount of protein available for digestion in the small intestine. ${ }^{12}$ Tannins can also interact with digestive enzymes, such as $\alpha$-glycosidase, $\alpha$-amylase, lipase, pepsin, trypsin, and chymotrypsin, and thus inhibit their enzymatic activities. ${ }^{14,15}$ These interactions are mostly regulated by non-covalent binding, i.e. van der Waals forces, hydrogen bonding, and other electrostatic forces. ${ }^{14}$ Tannins can form soluble and/or insoluble complexes with proteins, and the tannin-protein interactions are both tannin- and protein-specific. ${ }^{16}$ The studies on the effects of 27 individual ETs and 7 galloylglucoses and gallotannins on the egg hatching of pathogenic parasite Haemonchus contortus showed that several compounds have antiparasitic properties and clear structureactivity relationships were observed. ${ }^{8}$ The mechanisms of action remained unclear but the main reason seemed to be that tannins bind to egg shell proteins and thereby disturb the egg hatching process. ${ }^{8}$

Isothermal titration calorimetry (ITC) is an ideal technique to measure biological binding interactions, such as the interactions between the tannin and the protein. ${ }^{17-24}$ ITC can be used to measure the 
44

45

thermodynamics of the interaction, i.e. the binding constant $\mathrm{K}$, the enthalpy of binding $\left(\Delta \mathrm{H}_{\mathrm{obs}}\right)$ and the stoichiometry or number of binding sites (n). ${ }^{24}$ Most of the ITC studies on the interaction between tannins and proteins have focused on proanthocyanidins. ${ }^{19-21,23}$ Oligomeric and polymeric proanthocyanidins cannot be purified as individual compounds and therefore mainly proanthocyanidin fractions have been used. This makes the interpretation of results and the determination of thermodynamic binding parameters more difficult. ${ }^{23}$ The only exceptions are monomeric flavan-3-ols and cocoa proanthocyanidins consisting of epicatechin monomers which have been separated into different oligomers and studied in detail by ITC. ${ }^{20,23}$

In our previous study, we utilized a unique series of oligomeric tellimagrandin I -based ETs and studied their interaction with BSA by ITC. ${ }^{22}$ The ET series from tetramers to octa-undecamers enabled the evaluation of the effect of the molecular size on the interaction and we could decouple the other structural features. The interactions of ETs with BSA revealed strong similarities: Enthalpy showed an increasing trend from the dimer to larger oligomers. Our studies highlighted the importance of molecular flexibility to maximize binding between the tannin and protein surface. ${ }^{22}$ In this study, ET structures were selected so that they differed in the molecular flexibility and size and that they had different structural features (Fig. 1). These features included, for example, the tautomeric forms of the glucose core (glucopyranose versus acyclic core), different functional groups in their structures or the position of free hydroxyl group at $\mathrm{C}-1$ ( $\alpha$ and $\beta$ anomers). In addition, two proteins were used: BSA, a model for the globular proteins, and gelatin, a model for flexible proline-rich proteins.

Altogether, 12 ETs were selected and purified from different plant sources and their interactions were studied with BSA and gelatin by ITC. The aim was to broaden the knowledge on tannin-protein interactions and to study in detail how efficient different ETs are at binding with different proteins and to characterize the thermodynamics of these bindings. 
67

68

\section{MATERIALS AND METHODS}

(1)

(1)

Isolation and Characterization of ETs. ETs were extracted, isolated and purified from plant extracts and characterized by the methods previously described., ${ }^{4,22,25-28}$ The plant material was collected and placed directly into 10 bottles of $1 \mathrm{~L}$, which were then immediately filled with acetone, transferred to the laboratory, and stored in a cold room $\left(4^{\circ} \mathrm{C}\right)$ prior to the isolation of ellagitannins..$^{22}$ The preliminary fractionation was performed by Sephadex LH-20 chromatography and the final purifications of ellagitannins were made by preparative and semipreparative HPLC; all steps were followed by UPLC-ESI-MS. ${ }^{22}$ The ellagitannins were identified based on their chromatographic elution order, UV spectra, molecular ions and characteristic fragment ions based on our previous work and literature as shown in Table 1. Pure ellagitannins were concentrated to the water phase and freeze-dried. The individual ellagitannins, their purities obtained by UPLC at $280 \mathrm{~nm}$ and the electrospray ionization mass spectrometric identification are presented in Table 1. .Monomeric ETs with a glycopyranose core, tellimagrandin I and tellimagrandin II (1 and 2 in Fig. 1), were isolated from the meadowsweet inflorescence (Filipendula ulmaria) $)^{29-31}$ and geraniin ( 3 in Fig. 1) from the wood cranesbill leaves (Geranium sylvaticum) ${ }^{32}$. Acyclic ETs castalagin and vescalagin (4 and 5 in Fig. 1) were isolated from the purple loosestrife flowers and leaves (Lythrum salicaria) $)^{30,31,33}$ ) and castavaloninic and vescavaloninic acids (6 and 7 in Fig. 1) from the English oak acorns (Quercus robur) $)^{34,35}$. The stereochemistry of castalagin and vescalagin were lately reinvestigated by computational methods and the nonahydroxytriphenoyl group (NHTP) was found to exist in $(S, R)$ configuration. ${ }^{36,37}$ Therefore, it is feasible that the NHTP group of vescavaloninic and castavaloninic acids is also in $(S, R)$ configuration. Dimeric agrimoniin (8 in Fig. 1) was from the silverweed leaves (Potentilla anserina) $)^{25,31,38}$, gemin A (9 in Fig. 1) from the wood avens leaves (Geum urbanum ${ }^{25,39}$, and sanguiin H-6 and roshenin C (10 and 11 in Fig. 1) from the raspberry leaves (Rubus idaeus) ${ }^{25,38,40}$. In addition, trimeric lambertianin C (12 in Fig. 1) was isolated from the raspberry leaves.

Isothermal Titration Calorimetry. A NanoITC instrument (TA Instruments Ltd., Crawley, West Sussex, UK) was used to measure the thermodynamics of titrations of ET into BSA (purity $\geq 98 \%$, lyophilized powder, $66 \mathrm{kDa}$; Sigma-Aldrich, St. Louis, US, CAS 9048-46-8) or into gelatin (Gelatin, type B 
94

derived from lime-cured tissue, purity approx. 225 Bloom which is proportional to the average molecular mass of $50 \mathrm{kDa}$, Sigma-Aldrich, CAS 9000-70-8). The measurements were performed as earlier described. ${ }^{22}$ All solutions were prepared in $50 \mathrm{mM}$ citrate buffer adjusted to $\mathrm{pH}$ 6. In a typical measurement for the interaction between the ET and BSA, 20 or $30 \mu \mathrm{M}$ BSA solution was placed in the $950 \mu \mathrm{L}$ sample cell of the calorimeter and $3 \mathrm{mM}$ ET solution was loaded into the injection syringe. The ET studied was titrated into the sample cell at $298 \mathrm{~K}$ as a sequence of 24 injections of $10 \mu \mathrm{L}$ aliquots. The time delay between the injections was $360 \mathrm{~s}$. Each ET-BSA interaction was measured at least with three replicates.

In a typical measurement for the interaction between ET and gelatin, different gelatin concentrations were used depending on the strength of the interactions. The different gelatin contents were $0.3,0.5,0.75,1.0,1.5$ and $2.0 \mathrm{mg} / \mathrm{mL}$. To get the molarities of the solution, the content of the solution was divided with the estimated molecular mass of gelatin $(50000 \mathrm{~g} / \mathrm{mol})$. The molarities of the gelatin solutions were thus approximately $6,10,15,20,30$ and $40 \mu \mathrm{M}$, respectively. Each ET-gelatin interaction was measured at least with three replicates.

Raw data were obtained as plots of heat $(\mu \mathrm{J})$ against injection number and exhibited a series of peaks for each injection. Examples of thermograms are available in figures S1-S6 in Supporting Information. The plots of raw heat data were transformed using the NanoAnalyze Data Analysis software (version 2.4.1., TA instruments) to obtain a plot of observed enthalpy change per mole of injectant $\left(\Delta \mathrm{H}_{\mathrm{obs}}, \mathrm{kJ} / \mathrm{mol}\right)$ against molar ET:BSA ratio. The control data of ellagitannin titrated into buffer were always subtracted from the sample data as it was known that ellagitannins tend to selfassociate into aggregates and then undergo an endothermic process of deaggregation when titrated from the syringe into buffer. ${ }^{19,22}$ Data fits and estimated binding parameters were obtained in two different ways: using a single set of multiple binding sites and a model for two independent sets of multiple binding sites. The quality of fits was determined by standard deviation. 


\section{RESULTS AND DISCUSSION}

ITC Binding Isotherms and Data Fitting for the ET/BSA Interaction. The interactions of twelve individual ETs (Figure 1) with BSA were studied by ITC. These ETs included three cyclic ET monomers, namely tellimagrandin I and tellimagrandin II and geraniin (ITC isotherms shown in Figure 2), four ET dimers, i.e. sanguiin H-6, roshenin C, agrimoniin and gemin A, and one ET trimer, i.e. lambertianin C (Fig. 3), and four acyclic ET monomers, namely castalagin, vescalagin, castavaloninic acid and vescavaloninic acid (Fig. 4).

Figures 2 and 3 show the ITC binding isotherms for the cyclic ET monomers, dimers and trimer binding to BSA. For these ET-BSA systems, an exothermic interaction was observed, and the interaction became less exothermic with the increasing injection number (increase in the tannin to protein molar ratio) as the binding sites of BSA became saturated. All experiments were performed in triplicate and using different concentrations of BSA, varying from $10 \mu \mathrm{M}$ to $40 \mu \mathrm{M}$ depending on the ET and the observed changes of enthalpy were detected. The interaction was not affected by BSA concentration, which suggested no evidence of co-operative binding as previously reported for oligomeric ETs. ${ }^{22}$

The data fittings were performed using two different binding models. One assumed a single set of multiple binding sites (later called as single-site model) and the other one two independent sets of multiple binding sites (later called as two-site model). ${ }^{21}$ For sanguiin H-6 and lambertianin C, the first data points of the titration isotherm were not used in order to fit the data both in two-site and one-site models (Fig. 3C and D). We have observed similar shapes in tannin-protein binding isotherms before and have suggested that this could indicate synergism in protein binding, such that the presence of ellagitannin already bound to gelatin has an effect on the binding of subsequent tannin molecules. ${ }^{19}$ There are also other possibilities that could explain this trend since there could be competing endothermic and exothermic interactions at play. In general, it can be seen that both binding models visually fit the data well for all of the ET/BSA systems with little difference in the agreement of the data fit curves and the data points for both binding models. Where a two-site model was used the second site showed usually a weaker binding with $K_{a 2}$ in the region of $10^{1}-10^{3} \mathrm{M}^{-1}$ (Table 2 and 3) and a single-site model was able to equally well represent the data. In some cases, see for example lambertianin C and BSA (Fig. 3D), the two-site model clearly exhibited a slightly better fit to the data than the single-site binding model. Similar observation were made in our previous study ${ }^{22}$, and therefore, the fit 
parameters for both binding models are shown in Tables 2 and 3. In addition, the estimated entropies for the ellagitannin-BSA interactions are presented as Supporting Information in Table S1. However, as all the interactions between ETs and BSA fit to the one-site model there is no clear justification for increasing the complexity of the model used to fit this data and therefore we will discuss the interactions between BSA and ETs based on the fittings obtained by the single-site model.

The ETs could be classified into three different groups based on the strength of their interactions with BSA; i.e. stronger, moderate and weaker interaction: i) Six ETs with a glupyranose core, i.e. tellimagrandin I, tellimagrandin II, agrimoniin, gemin A, sanguiin H-6, and lambertianin C, had the strongest interactions with BSA and the thermodynamic binding parameters could be estimated for these interactions (Tables 2 and 3). ii) Two ETs with a glucopyranose core, i.e. geraniin and roshenin C, had moderate interactions with BSA (Figs. 2 and 3), and for these it was difficult to produce a clear fit to the data and therefore we have less confidence in our estimated thermodynamic binding parameters for these ET/BSA interactions. iii) All acyclic ETs, i.e. castalagin, vescalagin, castavaloninic acid, and vescavaloninic acid, had no interaction or very weak interactions with BSA (Fig. 4) and no fits or thermodynamic binding parameters were obtained. Therefore, it was immediately evident that binding of the ETs to BSA were stronger for ETs with a cyclic core than for those with an acyclic glucose core.

Both sanguiin $\mathrm{H}-6$ and lambertianin $\mathrm{C}$ binding to BSA exhibited an increase in $\Delta \mathrm{H}$ during early injection numbers (low molar ratio) which indicates that the presence of ET in the BSA/ET solution results in an initial increase in binding. This may indicate that previously bound ET on the protein is able to facilitate the binding of subsequent ET molecules injected into the solution. Such features in ITC binding isotherms have been seen in other studies as an indication of this kind of co-operative binding. We also noted above that gemin A exhibited different behavior in cases where the experimental procedure was different, and this may be explained if the method was able to provide enough time between injections to maximize the effect of this co-operative binding.

Table 2 and Figure 2 compare our three monomeric cyclic ETs and show that the binding with BSA is strongest for tellimagrandin I $\left(K_{a}=1.8 \times 10^{4} \mathrm{M}^{-1}\right)$ compared to tellimagrandin II $\left(K_{a}=7.3 \times 10^{-3} \mathrm{M}^{-1}\right)$. As could be expected, the weakest binding with BSA of our ET monomers studied was with geraniin, which also exhibits a more rigid constrained structure compared to tellimagrandin I and II. For all these three ETs, 
$\Delta \mathrm{H}$ is similar. It is not clear if there is any substantial trend or information that can be gained from the values of $n$ (number of ET molecules binding to each BSA molecule). Our fit consistently gave tellimagrandin II a relatively high value for $\mathrm{n}$ compared to the other ETs (Table 2). Previously, there has been a suggestion that weak binding between tannins and BSA can result from unspecific adsorption that has a weak binding affinity to the BSA surface. The weak $K_{a}$ seen for tellimagrandiin II coincides with a higher fitted value for $\mathrm{n}$ and may well indicate such an adsorption event. To further support the link between high values for $\mathrm{n}$ and non-selective adsorption, tellimagrandin II has poorer water-solubility than other ETs (based on unpublished octanol-water coefficients), and thus a greater tendency towards surface adsorption. This type of adsorption might also be expected for ETs with greater flexibility in their structure allowing for less conformational restraints and increased ability to non-selectively binding to protein surfaces. ${ }^{17,18}$ Our dimeric and trimeric ETs show variations in binding that are greater than that seen for tellimagrandin II and geraniin, with the trimeric lambertianin $\mathrm{C}$ exhibiting the strongest interaction $\left(K_{a}=1.1 \times 10^{5} \mathrm{M}^{-1}\right)$. Overall, we see a link between the oligomerization and the strength of interaction between ET and BSA. As seen here, our previous studies found that the interaction of monomeric tellimagrandin I with BSA was stronger, in terms of $\mathrm{K}_{a}$, than expected in relation to the oligomeric series of ETs..$^{22}$ However, that oligomeric series contained similar monomeric units in all the oligomers, which enabled the direct comparison of the interaction between the different oligomers based on the number of monomeric units and without the effects of the other structural features, such as functional groups. ${ }^{22}$ In general for polyphenols, the increase in the binding affinity with the molecular size have also been observed previously even if other differences in the molecular structures are present. ${ }^{41}$ However, for quercetin and quercetin 3-O- $\beta$-D-glucopyranoside binding with BSA, the opposite has been reported. ${ }^{42}$

The dimeric ETs that we investigated exhibited similar behavior in terms of their binding to BSA, agrimoniin, gemin A and sanguiin H-6 had equilibrium binding constants varying between 1.1-1.7 $\times 10^{4}$ $\mathrm{M}^{-1}$, and similar values for $\Delta \mathrm{H}$ and $\mathrm{n}$. Agrimoniin and gemin $\mathrm{A}$ are structurally closely similar; the main difference is that agrimoniin contains four HHDP groups whereas gemin A has three HHDP groups and two free galloyl groups and that the orientation at $\mathrm{C}-1$ of the glucose is $\alpha$ in agrimoniin and $\beta$ in gemin $\mathrm{A}$. Two of the binding parameters for gemin $\mathrm{A}, \Delta \mathrm{H}_{1}=-45 \mathrm{~kJ} \mathrm{~mol}^{-1}$ and $\mathrm{n}=14$, are similar to the previously measured values, $\Delta \mathrm{H}_{1}=-47 \mathrm{~kJ} \mathrm{~mol}^{-1}$ and $\mathrm{n}_{1}=13$, but the equilibrium binding constant $1.1 \times 10^{4} \mathrm{M}^{-1}$ is different to the 
previous one $1.8 \times 10^{6} \mathrm{M}^{-1} .{ }^{17}$ In previous study, ETs were titrated into the sample cell in two titration events where the syringe was filled within the run, i.e. first the sequence of 24 injections, then the filling of the syringe and then the sequence of 24 injections. ${ }^{17}$ The current measurements were performed as a single titration event without any additional distractions to the titration, and this means that the titration volume and time taken for the experiment to complete are different. Sanguiin H-6 and roshenin C only differ by the latter lacking one HHDP group, but still they showed very different behaviors in terms of BSA binding. Our fits for roshenin C are poor because of the observed weakness of the interaction with small variation in $\Delta \mathrm{H}$ and show significant variability in terms of the strong binding site between the two binding model fits. We are unable to identify any structural reason to explain why the roshenin/BSA interaction is weak and we are unable to provide confident fit parameters for this ET. Nevertheless, this finding shows that not only galloyls are important for increasing tannin-protein interaction, but also the presence vs. absence makes a difference.

Acyclic ETs castalagin, vescalagin, castavaloninic and vescavaloninic acids had very weak interactions with BSA based on the isotherms (Fig. 4). No reliable fits or thermodynamic binding parameters were obtained. The weak interaction cannot be due to low water-solubility as acyclic ETs are very watersoluble. ${ }^{28}$ The other reason could be the relatively rigid conformation of acyclic ETs having NHTP groups in their structures (Fig. 1). The interaction between vescalagin and BSA has been previously studied and found to be weak in comparison to other ETs. ${ }^{17}$ The interaction between acyclic ETs and BSA were so weak that we could not evaluate the effects of other structural features, such as the role of free $\mathrm{COOH}$ present in vescavaloninic and castavaloninic acids or the effects of the $\alpha$ or $\beta$ orientation at $\mathrm{C}-1$ of the glucose.

ITC Binding Isotherms and Data Fitting for the ET/Gelatin Interaction. The interaction of the ETs with gelatin is shown in Figures 5-7 and Tables 4-5. The cyclic ET monomers in Fig. 5 and the cyclic ET dimers and trimer in Fig. 6 all show an exothermic interaction between the ET and gelatin showing a gradual decrease in exothermicity as the binding sites of gelatin become saturated. In general, the interaction was stronger between gelatin and ETs than between BSA and ETs. As for our ET-BSA data, the data fittings were performed using the single-site model and the two-site model. However, for the interaction with gelatin it can be seen that overall the two-site model fit the data better. For example, for the interaction between gemin A and gelatin, the two-site model clearly visually exhibited a closer fit (Fig. 6B) and the calculated SD for the fits and thermodynamic binding parameters (Table 5) also supported the presence of the secondary binding 
site. Similar observations were made for all the other ETs (Figs. 5 and 6, Tables 4 and 5). For the trimer ET, lambertianin C (Fig. 6D), the data showed no evidence of a second-site binding and the ET-gelatin binding isotherm showed a strong primary binding site. As for our BSA data, the fit parameters for both binding models are shown in Tables 4 and 5. In addition, the estimated entropies for the ellagitannin-gelatin interactions are presented as Supporting Information in Table S1. Given that the interaction between gelatin and ETs are approximately ten-fold stronger (see $\mathrm{K}_{a l}$ values), it may not be surprising that a second, perhaps less specific binding (or non-selective adsorption to the protein) could be observed.

Similarly to the interaction between different ETs and BSA, it was evident that the interactions between ETs and gelatin were stronger for ETs with a glucopyranose core than for acyclic ETs as the observed changes of enthalpy were higher for these ETs than for acyclic ETs (Fig. 6 in comparison to Fig. 7). The ETs can be classified into two groups based on the strength of their interactions with gelatin. i) Seven ETs with a glucopyranose core, i.e. tellimagrandin I, tellimagrandin II, agrimoniin, gemin A, sanguiin H-6, lambertianin $\mathrm{C}$, and roshenin $\mathrm{C}$ had stronger interactions with gelatin (Figs. 5 and 6) and the thermodynamic binding parameters could be estimated for these interactions (Tables 4 and 5). ii) Four acyclic ETs, i.e. castalagin, vescalagin, castavaloninic acid, and vescavaloninic acid, had no interaction or very weak interactions with gelatin (Fig. 7) and no fits or thermodynamic binding parameters were obtained. For both BSA and gelatin, geraniin is an exception to this rule, where it behaved more like the acyclic ETs and for gelatin no binding parameters could be obtained.

In general, the interactions between gelatin and ETs are independent of ET concentration as also seen to the interaction between ETs and BSA. However, there seems to be some exceptions, see for example geraniin in Fig. 5C which shows the ITC data for the titration of geraniin into gelatin solutions of varying concentrations (two replicates for $20 \mu \mathrm{M}$ gelatin, $30 \mu \mathrm{M}$ gelatin and $40 \mu \mathrm{M}$ gelatin). The shapes of the isotherms are completely different in comparison to those of other ETs with a glucopyranose core. Typically the interaction between the protein and ET gets smaller with increasing injections (molar ratio) as the saturation of the binding site on the protein occurs (Fig. 6 shows example of this usual behavior). However, initially at low molar ratio the interaction between gelatin and geraniin gets stronger when more geraniin is added (Fig. 5C) and the shape of the interaction changes with the increasing protein concentration. The biphasic shape of the isotherms and dependence on protein concentration are similar to the ITC isotherms of 
SDS titration into lysozyme. ${ }^{43}$ There is a gradual increase in the binding enthalpy that reaches a plateau region, with a maximum enthalpy change of the binding of approximately $-20 \mathrm{~kJ} / \mathrm{mol}$, followed by a decrease in the measured enthalpy change as the protein binding sites become saturated. This would suggest that initial binding is co-operative in that the presence of pre-bound ET initially promotes the exothermicity of the interaction. Also, the binding is stronger in a higher protein concentration solution which could indicate oligomerization of the protein and more complex protein-ET intermolecular structures. Others have also observed biphasic binding isotherms in cases where the ligand induces oligomerization of the protein. ${ }^{44}$ It is possible given the structure of gelatin that geraniin is able to alter its secondary structure to promote oligomerization. Although less pronounced, the acyclic ETs (Fig. 7), particularly castalagin, appear to exhibit a similar behavior.

For the interaction between the ETs with a glycopyranose core and gelatin, there is a clear link between strength of binding and oligomerization of the ETs. Generally weaker interactions observed for the monomers $\left(\mathrm{K}_{a l}\right.$ range $\left.0.8-1.8 \times 10^{5} \mathrm{M}^{-1}\right)$ compared to the dimers $\left(\mathrm{K}_{a l}=1.5-13 \times 10^{5} \mathrm{M}^{-1}\right)$, and a strongest interaction seen for the trimer ET $\left(\mathrm{K}_{a 1}=19 \times 10^{5} \mathrm{M}^{-1}\right.$, Table 5).

In summary, we had a selection of purified ETs and were able to determine their interactions with selected proteins, i.e. BSA and gelatin, in addition to the thermodynamic parameters related to this interaction. Given the importance of this interaction in defining the biological activities of these molecules and the current difficulties in studying such systems, the use of purified tannins provides structure-function information that has previously been difficult to derive from less purified tannin fractions. BSA and gelatin model different aspects of protein structure; BSA as a globular well-characterized protein and gelatin as a proline-rich random coil structure that are also exhibited in salivary proline-rich proteins. Our data clearly shows a difference in protein binding behavior of ETs with cyclic and acyclic glucose cores, showing very weak binding to the acyclic structures where the ET tends to have a less open structure and relatively rigid conformation. Our data show that ETs with a glucopyranose structure are able to bind more strongly to the protein. These observations were observed for binding to both proteins. As expected, the binding to gelatin was stronger than to BSA which indicates the importance of the more flexible protein structure on tannin binding behavior. The binding was also dependent on the oligomerization of the ET, with the larger ET binding more strongly. It is clear that the ETs bind to multiple sites on the surface of the protein and those able to wrap around the protein structure and increase foot-holds to the protein surface are able to bind more strongly. For 
the ET-gelatin binding, a two-site binding model better described the interaction of the dimeric ETs and we observe for all ET-protein interactions relatively high values for $n$; this shows that the ET-protein interaction is not dependent on a specific binding domain but is less selective with regions of higher and lower binding affinity that may be related to hydrophobicity or surface charged regions rather than specific tertiary binding regions. Thus, it may be easier to consider these interactions as a non-selective adsorption behavior particularly when considering the second-binding site.

In most cases, a tannins biological activity, for example as an anthelmintic compound, may be defined by how it interacts with proteins. Our data showed that acyclic ETs with NHTP groups had weaker interaction with proteins than the ETs with a glucopyranose core. Similarly, the presence of NHTP groups was shown to be an important factor in the anthelmintic effects of ETs, as detected by a decrease in the inhibition activity of ETs against egg hatching of $H$. contortus. ${ }^{8}$ It is thus probable that these types of ITC experiments described in this paper are able to reveal the possible significant or non-significant role of tannins in many aspects related to tannin-ruminant interactions.

\section{ABBREVIATIONS USED}

BSA, bovine serum albumin; DAD, diode array detection; ESI, electrospray ionization; ET, ellagitannin; HHDP, hexahydroxydiphenoyl; HPLC, high-performance liquid chromatography; ITC, isothermal titration calorimetry; MS, mass spectrometry; NHTP, nonahydroxytriphenoyl; UPLC-, ultra-performance liquid chromatography

\section{ACKNOWLEDGMENTS}

Anu Tuominen, Mika Karonen and other gatherers are thanked for their help in the collection of plant materials. Atte Tuominen, Hanna-Mari Salmia, Milla Leppä and Jorma Kim are acknowledged for their help in the isolation and purification of ETs, and Marina A. Dobreva for her help with the ITC measurements.

\section{ASSOCIATED CONTENT}


314

315

316

317

318

319

320

321

322

323

324

325

326

327

328

329

330

331

332

333

334

335

336

337

338

\section{*S Supporting Information}

The Supporting Information is available free of charge on the ACS Publications website at DOI: $\mathrm{x}$.

Figures S1-S6. Examples of thermograms for the interaction of ellagitannins with BSA and gelatin. The thermograms include the raw heat data $(\mu \mathrm{J} / \mathrm{s})$ from where the control experiment is not subtracted.

Table S1. Estimated entropies for the interaction of ellagitannins with BSA and gelatin fitted by two-site and one-site binding models.

(PDF)

\section{REFERENCES}

(1) Pichersky, E.; Lewinsohn, E. Convergent Evolution in Plant Specialized Metabolism. Annu. Rev. Plant Biol. 2011, 62, 549-566. https://doi.org/10.1146/annurev-arplant-042110-103814.

(2) Salminen, J.-P. Two-Dimensional Tannin Fingerprints by Liquid Chromatography Tandem Mass Spectrometry Offer a New Dimension to Plant Tannin Analyses and Help to Visualize the Tannin Diversity in Plants. J. Agric. Food Chem. 2018, 66, 9162-9171. https://doi.org/10.1021/acs.jafc.8b02115.

(3) Salminen, J.-P.; Karonen, M. Chemical Ecology of Tannins and Other Phenolics: We Need a Change in Approach. Funct. Ecol. 2011, 25 (2), 325-338. https://doi.org/10.1111/j.1365-2435.2010.01826.x.

(4) Karonen, M.; Parker, J.; Agrawal, A.; Salminen, J.-P. First Evidence of Hexameric and Heptameric Ellagitannins in Plants Detected by Liquid Chromatography/Electrospray Ionisation Mass Spectrometry. Rapid Commun. Mass Spectrom. 2010, 24 (21), 3151-3156. https://doi.org/10.1002/rcm.

(5) Okuda, T.; Yoshida, T.; Hatano, T.; Ito, H. Ellagitannins Renewed the Concept of Tannins. In Chemistry and biology of ellagitannins: An underestimated class of bioactive plant polyphenols; Quideau, S., Ed.; World Scientific: Singapore, 2009; pp 1-54.

(6) Yoshida, T.; Hatano, T.; Ito, H.; Okuda, T. Structural Diversity and Antimicrobial Activities of 

polyphenolsiology Ellagitannins: An Underestimated Class of Bioactive Plant Polyphenols; Quideau, S., Ed.; World Scientific Publishing: Singapore, 2009; pp 55-93.

Quideau, S.; Deffieux, D.; Douat-Casassus, C.; Pouységu, L. Plant Polyphenols: Chemical Properties,

(8) Engström, M. T. T.; Karonen, M.; Ahern, J. R. R.; Baert, N.; Payré, B.; Hoste, H.; Salminen, J.-P. 840-851. https://doi.org/10.1021/acs.jafc.5b05691.

(9) Lowry, J.; McSweeney, C.; Palmer, B. Changing Perceptions of the Effect of Plant Phenolics on

(10) Min, B. R.; Hart, S. P. Tannins for Suppression of Internal Parasites. J. Anim. Sci. 2002, 81, 102-109.

(11) Min, B.; Barry, T.; Attwood, G.; McNabb, W. The Effect of Condensed Tannins on the Nutrition and Health of Ruminants Fed Fresh Temperate Forages: A Review. Anim. Feed Sci. Technol. 2003, 106, 3-19. https://doi.org/10.1016/S0377-8401(03)00041-5.

(12) Mueller-Harvey, I.; Bee, G.; Dohme-Meier, F.; Hoste, H.; Karonen, M.; Kölliker, R.; Lüscher, A.; Niderkorn, V.; Pellikaan, W. F.; Salminen, J.-P.; et al. Benefits of Condensed Tannins in Forage Legumes Fed to Ruminants: Importance of Structure, Concentration, and Diet Composition. 2019, 885 (june), 861-885. https://doi.org/10.2135/cropsci2017.06.0369.

(13) Baert, N.; Pellikaan, W. F. W. F.; Karonen, M.; Salminen, J.-P. A Study of the Structure-Activity Relationship of Oligomeric Ellagitannins on Ruminal Fermentation in Vitro. J. Dairy Sci. 2016, 99 (10), 8041-8052. https://doi.org/10.3168/jds.2016-11069.

(14) Martinez-Gonzalez, A. I.; Díaz-Sánchez, Á. G.; de la Rosa, L. A.; Vargas-Requena, C. L.; BustosJaimes, I.; Alvarez-Parrilla, E. Polyphenolic Compounds and Digestive Enzymes: In Vitro NonCovalent Interactions. Molecules 2017, 22, 669. https://doi.org/10.3390/molecules22040669.

(15) Barrett, A. H.; Farhadi, N. F.; Smith, T. J. Slowing Starch Digestion and Inhibiting Digestive Enzyme Activity Using Plant Flavanols/Tannins - A Review of Efficacy and Mechanisms. LWT - Food Sci. 
Technol. 2018, 87, 394-399. https://doi.org/10.1016/j.lwt.2017.09.002.

(16) Asquith, T. N.; Butler, L. G. Interactions of Condensed Tannins with Selected Proteins. Phytochemistry 1986, No. 7, 1591-1593.

(17) Dobreva, M. A.; Green, R. J.; Mueller-Harvey, I.; Salminen, J.-P.; Howlin, B. J.; Frazier, R. A. Size and Molecular Flexibility Affect the Binding of Ellagitannins to Bovine Serum Albumin. J. Agric. Food Chem. 2014, 62 (37), 9186-9194. https://doi.org/10.1021/jf502174r.

(18) Dobreva, M. A.; Frazier, R. A.; Mueller-Harvey, I.; Clifton, L. A.; Gea, A.; Green, R. J. Binding of Pentagalloyl Glucose to Two Globular Proteins Occurs via Multiple Surface Sites.

Biomacromolecules 2011, 12 (3), 710-715. https://doi.org/10.1021/bm101341s.

(19) Frazier, R. A.; Papadopoulou, A.; Mueller-Harvey, I.; Kissoon, D.; Green, R. J. Probing ProteinTannin Interactions by Isothermal Titration Microcalorimetry. J. Agric. Food Chem. 2003, 51 (18), 5189-5195. https://doi.org/10.1021/jf021179v.

(20) Frazier, R. A.; Papadopoulou, A.; Green, R. J. Isothermal Titration Calorimetry Study of Epicatechin Binding to Serum Albumin. J. Pharm. Biomed. Anal. 2006, 41 (5), 1602-1605. https://doi.org/10.1016/j.jpba.2006.02.004.

(21) Deaville, E. R.; Green, R. J.; Muller-Harvey, I.; Willoughby, I.; Frazier, R. A. Hydrolyzable Tannin Structures Influence Relative Globular and Random Coil Protein Binding Strengths. J. Agric. Food Chem. 2007, 55 (11), 4554-4561. https://doi.org/10.1021/jf063770o.

(22) Karonen, M.; Oraviita, M.; Mueller-Harvey, I.; Salminen, J.-P.; Green, R. J. Binding of an Oligomeric Ellagitannin Series to Bovine Serum Albumin (BSA): Analysis by Isothermal Titration Calorimetry (ITC). J. Agric. Food Chem. 2015, 63 (49), 10647-10654. https://doi.org/10.1021/acs.jafc.5b04843.

(23) Kilmister, R. L.; Faulkner, P.; Downey, M. O.; Darby, S. J.; Falconer, R. J. The Complexity of Condensed Tannin Binding to Bovine Serum Albumin - An Isothermal Titration Calorimetry Study. Food Chem. 2016, 190, 173-178. https://doi.org/10.1016/j.foodchem.2015.04.144.

(24) Lewis, E. A.; Murphy, K. P. Isothermal Titration Calorimetry. Protein-Ligand Interact. 2005, 305 (7), 001-016. https://doi.org/10.1385/1-59259-912-5:001.

(25) Moilanen, J.; Salminen, J.-P. Ecologically Neglected Tannins and Their Biologically Relevant 
Activity: Chemical Structures of Plant Ellagitannins Reveal Their in Vitro Oxidative Activity at High PH. Chemoecology 2008, 18 (2), 73-83. https://doi.org/10.1007/s00049-007-0395-7.

(26) Salminen, J.-P.; Ossipov, V.; Loponen, J.; Haukioja, E.; Pihlaja, K. Characterisation of Hydrolysable Tannins from Leaves of Betula Pubescens by High-Performance Liquid Chromatography-Mass Spectrometry. J. Chromatogr. A 1999, 864 (2), 283-291. https://doi.org/10.1016/S00219673(99)01036-5.

(27) Salminen, J.-P.; Ossipov, V.; Haukioja, E.; Pihlaja, K. Seasonal Variation in the Content of Hydrolysable Tannins in Leaves of Betula Pubescens. Phytochemistry 2001, 57 (1), 15-22. https://doi.org/10.1016/S0031-9422(00)00502-1.

(28) Salminen, J.-P.; Karonen, M.; Sinkkonen, J. Chemical Ecology of Tannins: Recent Developments in Tannin Chemistry Reveal New Structures and Structure-Activity Patterns. Chem. - A Eur. J. 2011, 17 (10), 2806-2816. https://doi.org/10.1002/chem.201002662.

(29) Okuda, T.; Yoshida, T.; Hatano, T.; Yazaki, K.; Ashida, M. Ellagitannins of the Casuarinaceae, Stachyuraceae and Myrtaceae. Phytochemistry 1980, 21 (12), 2871-2874. https://doi.org/10.1016/0031-9422(80)85058-8.

(30) Rauha, J.-P.; Wolfender, J.-L.; Salminen, J.-P.; Pihlaja, K.; Hostettmann, K.; Vuorela, H. Characterization of the Polyphenolic Composition of Purple Loosestrife (Lythrum Salicaria). Zeitschrift fur Naturforsch. - Sect. C J. Biosci. 2001, 56 (1-2), 13-20. https://doi.org/10.1515/znc2001-1-203.

(31) Moilanen, J.; Sinkkonen, J.; Salminen, J.-P. Characterization of Bioactive Plant Ellagitannins by Chromatographic, Spectroscopic and Mass Spectrometric Methods. Chemoecology 2013, 23 (3), 165179. https://doi.org/10.1007/s00049-013-0132-3.

(32) Tuominen, A.; Toivonen, E.; Mutikainen, P.; Salminen, J.-P. Defensive Strategies in Geranium Sylvaticum. Part 1: Organ-Specific Distribution of Water-Soluble Tannins, Flavonoids and Phenolic Acids. Phytochemistry 2013, 95, 394-407. https://doi.org/10.1016/j.phytochem.2013.05.013.

(33) Salminen, J.-P. J.-P.; Roslin, T.; Karonen, M.; Sinkkonen, J.; Pihlaja, K.; Pulkkinen, P. Seasonal Variation in the Content of Hydrolyzable Tannins, Flavonoid Glycosides, and Proanthocyanidins in Oak Leaves. J. Chem. Ecol. 2004, 30 (9), 1693-1711. 
https://doi.org/10.1023/B:JOEC.0000042396.40756.b7.

(34) Yarnes, C. T.; Boecklen, W. J.; Tuominen, K.; Salminen, J.-P. Defining Phytochemical Phenotypes: Size and Shape Analysis of Phenolic Compounds in Oaks (Fagaceae, Quercus ) of the Chihuahuan Desert. Can. J. Bot. 2006, 84 (8), 1233-1248. https://doi.org/10.1139/b06-076.

(35) Yarnes, C. T.; Boecklen, W. J.; Salminen, J.-P. No Simple Sum: Seasonal Variation in Tannin Phenotypes and Leaf-Miners in Hybrid Oaks. Chemoecology 2008, 18 (1), 39-51.

(36) Matsuo, Y.; Wakamatsu, H.; Omar, M.; Tanaka, T. Reinvestigation of the Stereochemistry of the CGlycosidic Ellagitannins, Vescalagin and Castalagin. Org. Lett. 2015, 17 (1), 46-49. https://doi.org/10.1021/o1503212v.

(37) Suvanto, J.; Tähtinen, P.; Valkamaa, S.; Engström, M. T.; Karonen, M.; Salminen, J.-P. Variability in Foliar Ellagitannins of Hippophaë Rhamnoides L. and Identification of a New Ellagitannin, Hippophaenin C. J. Agric. Food Chem. 2018, 66 (3), 613-620. https://doi.org/10.1021/acs.jafc.7b04834.

(38) Yoshida, T.; Feng, W.-S.; Okuda, T. Tannins and Related Polyphenols of Rosaceous Medicinal Plants. XII. Roshenins A-E, Dimeric Hydrolyzable Tannins from Rosa Henryi BOUL. Chem. Pharm. Bull. 1992, 40 (8), 1997-2001.

(39) Yoshida, T.; Maruyama, Y.; Memon, M. U.; Shingu, T.; Okuda, T. Gemins D, E and F, Ellagitannins from Geum Japonicum. Phytochemistry 1985, 24 (5), 1041-1046.

(40) Mullen, W.; Yokota, T.; Lean, M. E. J.; Crozier, A. Analysis of Ellagitannins and Conjugates of Ellagic Acid and Quercetin in Raspberry Fruits by LC-MSn. Phytochemistry 2003, 64 (2), 617-624. https://doi.org/10.1016/S0031-9422(03)00281-4.

(41) Ozdal, T.; Capanoglu, E.; Altay, F. A Review on Protein-Phenolic Interactions and Associated Changes. Food Res. Int. 2013, 51 (2), 954-970. https://doi.org/10.1016/j.foodres.2013.02.009.

(42) Martini, S.; Bonechi, C.; Rossi, C. Interaction of Quercetin and Its Conjugate Quercetin 3-O- $\beta-D-$ Glucopyranoside with Albumin as Determined by NMR Relaxation Data. J. Nat. Prod. 2008, 71 (2), 175-178. https://doi.org/10.1021/np070285u.

(43) Lad, M. D.; Ledger, V. M.; Briggs, B.; Green, R. J.; Frazier, R. A. Analysis of the SDS-Lysozyme Binding Isotherm. Langmuir 2003, 19 (12), 5098-5103. https://doi.org/10.1021/la0269560. 
451

452

453

454

455

456

457

458

459

460

461

462

463

464
(44) Thao, S.; Escalante-Semerena, J. C. Biochemical and Thermodynamic Analyses of Salmonella Enterica Pat, a Multidomain, Multimeric N-Lysine Acetyltransferase Involved in Carbon and Energy Metabolism. MBio 2011, 2 (5), 1-8. https://doi.org/10.1128/mBio.00216-11.

\section{AUTHOR INFORMATION}

\section{Corresponding authors}

*(M.K.) Tel: + 35829450 3179. E-mail: maarit.karonen@utu.fi.

* (R.J.G) Phone: +44 118378 8446. E-mail: rebecca.green@reading.ac.uk.

\section{Funding}

This research was funded by Academy of Finland (grants 251388 and 310549 to MK). Analyses and characterization of ETs on the UPLC-ESI-MS/MS system were made possible by a Strategic Research Grant of University of Turku (Ecological Interactions).

\section{Notes}

The authors declare no competing financial interest. 


\section{FIGURE CAPTIONS}

Figure 1. Individual ellagitannins studied for their interactions with BSA and gelatin. A refers to gallic acid, DHHDP to dehydrohexahydroxydiphenoyl group, G to galloyl group, GOD to linking between a galloyl and an HHDP group, GOG to linking between two galloyl groups, HHDP to hexahydroxydiphenoyl group and NHTP to nonahydroxytriphenoyl group.

Figure 2. Single-site (short dashed line) and two-site (long dashed line) binding models fitted to the experimental data ( $\mathbf{\square})$ for the interaction of monomeric ellagitannins with a glucopyranose core: tellimagrandin I (A), tellimagrandin II (B), and the ITC binding isotherms for the interaction of monomeric ellagitannin geraniin (C) with $20 \mu \mathrm{M}$ BSA in two replicate measurements ( $\square$ and $\square)$ and $30 \mu \mathrm{M}$ BSA $(\Delta)$ and $40 \mu \mathrm{M}$ BSA in two replicates $(\times$ and +$)$.

Figure 3. Single-site (short dashed line) and two-site (long dashed line) binding models fitted to the experimental data ( $\mathbf{m})$ for the interaction of the ellagitannin dimers with a glucopyranose core: agrimoniin (A), gemin A (B), sanguiin H-6 (C), and trimer lambertianin C (D) with $30 \mu \mathrm{M}$ BSA, and the ITC binding isotherms for the interaction of dimeric ellagitannin roshenin C (E) with $20 \mu \mathrm{M}$ BSA (- $)$ and $30 \mu \mathrm{M}$ BSA in two replicate experiments $(\Delta$ and $\times)$.

Figure 4. ITC binding isotherms for the interaction of acyclic ellagitannins castalagin (A) with $10 \mu \mathrm{M} \mathrm{BSA}$ (匹), $20 \mu \mathrm{M}$ BSA $(\Delta)$ and $30 \mu \mathrm{M}$ BSA ( $\times$ ), vescalagin (B) with $20 \mu \mathrm{M}$ BSA ( () and $30 \mu \mathrm{M}$ BSA in two replicate experiments $(\Delta$ and $\times$ ), castavaloninic acid (C) with $20 \mu \mathrm{M}$ BSA ( $(-)$ and $30 \mu \mathrm{M}$ BSA in two replicate experiments ( $\Delta$ and $\times$ ) and vescavaloninic acid (D) with $20 \mu \mathrm{M}$ BSA ( $(\bullet)$ and $30 \mu \mathrm{M}$ BSA in two replicate experiments $(\Delta$ and $\times)$.

Figure 5. Single-site (short dashed line) and two-site (long dashed line) binding models fitted to the experimental data (घ) for the interaction of ellagitannins with a glucopyranose core: tellimagrandin (A) I with $10 \mu \mathrm{M}$ gelatin and tellimagrandin II (B) with $20 \mu \mathrm{M}$ gelatin. In addition, ITC binding isotherms for the 
interaction of monomeric ellagitannin geraniin $(C)$ with $6 \mu \mathrm{M}$ gelatin in two replicate measurements $(\square$ and $\square$ ) and with $10 \mu \mathrm{M}$ gelatin $(\Delta)$ and $20 \mu \mathrm{M}$ gelatin $(\times)$.

Figure 6. Single-site (short dashed line) and two-site (long dashed line) binding models fitted to the experimental data ( $\mathbf{\square})$ for the interaction of ellagitannins with a glucopyranose core: agrimoniin (A), gemin A (B), sanguiin H-6 (C), lambertianin C (D), and roshenin C (E) with $20 \mu \mathrm{M}$ gelatin.

Figure 7. ITC binding isotherms for the interaction of acyclic ellagitannins castalagin (A), vescalagin (B), castavaloninic acid (C), and vescavaloninic acid (D) with $6 \mu \mathrm{M}$ gelatin (-), $10 \mu \mathrm{M}$ gelatin $(\Delta)$ and $20 \mu \mathrm{M}$ gelatin $(\times)$. 
Table 1. The Individual Ellagitannins Tested, Their Purities Obtained by UPLC at $280 \mathrm{~nm}$ and Electrospray Ionization Mass Spectrometric (ESI-MS) Identification

\begin{tabular}{|c|c|c|c|c|}
\hline No. & Ellagitannin & $\begin{array}{l}\text { Purity } \\
(\%)\end{array}$ & ESI-MS identification $(\mathrm{m} / \mathrm{z})$ & Literature \\
\hline 1 & Tellimagrandin I & 97.5 & $785[\mathrm{M}-\mathrm{H}]^{-}$ & 27,31 \\
\hline 2 & Tellimagrandin II & 97.9 & $937[\mathrm{M}-\mathrm{H}]^{-}, 301$ [ellagic acid-H] $]^{-}$ & 27,29 \\
\hline 3 & Geraniin & 98.3 & $951[\mathrm{M}-\mathrm{H}]^{-}, 933\left[\mathrm{M}-\mathrm{H}_{2} \mathrm{O}-\mathrm{H}\right]^{-}$, & 32 \\
\hline 4 & Castalagin & 99.6 & $\begin{array}{l}933[\mathrm{M}-\mathrm{H}]^{-}, 466[\mathrm{M}-2 \mathrm{H}]^{2-} \\
301 \text { [ellagic acid-H]- }\end{array}$ & $30,31,33$ \\
\hline 5 & Vescalagin & 94.1 & $\begin{array}{l}933[\mathrm{M}-\mathrm{H}]^{-}, 915\left[\mathrm{M}-\mathrm{H}_{2} \mathrm{O}-\mathrm{H}\right]^{-}, 466[\mathrm{M}-2 \mathrm{H}]^{2-} \\
457\left[\mathrm{M}-\mathrm{H}_{2} \mathrm{O}-2 \mathrm{H}\right]^{2-}, 301[\text { ellagic acid-H }]^{-}\end{array}$ & $30,31,33$ \\
\hline 6 & Castavaloninic acid & 99.6 & $1101[\mathrm{M}-\mathrm{H}]^{-}, 528[\mathrm{M}-\mathrm{COOH}-\mathrm{H}]^{2-}$ & 34,35 \\
\hline 7 & Vescavaloninic acid & 95.6 & $\begin{array}{l}1101[\mathrm{M}-\mathrm{H}]^{-}, 1083\left[\mathrm{M}-\mathrm{H}_{2} \mathrm{O}-\mathrm{H}\right]^{-}, \\
528[\mathrm{M}-\mathrm{COOH}-\mathrm{H}]^{2-} \\
519\left[\mathrm{M}^{-} \mathrm{H}_{2} \mathrm{O}-\mathrm{COOH}-\mathrm{H}\right]^{2-}, \\
301[\text { ellagic acid-H] }]^{-}\end{array}$ & 34,35 \\
\hline 8 & Agrimoniin & 97.7 & $934[\mathrm{M}-2 \mathrm{H}]^{2-}, 301$ [ellagic acid-H] $]^{-}$ & $25,29,31$ \\
\hline 9 & Gemin A & 98.2 & $935[\mathrm{M}-2 \mathrm{H}]^{2-}, 301$ [ellagic acid-H] $]^{-}$ & 25,39 \\
\hline 10 & Sanguiin H-6 & 97.6 & $934[\mathrm{M}-2 \mathrm{H}]^{2-}, 301$ [ellagic acid-H] $]^{-}$ & 25,40 \\
\hline 11 & Roshenin C & 93.8 & $783[\mathrm{M}-2 \mathrm{H}]^{2-}, 301$ [ellagic acid-H] $]^{-}$ & 38 \\
\hline 12 & Lambertianin $\mathrm{C}$ & 95.6 & $934[\mathrm{M}-3 \mathrm{H}]^{3-}, 301$ [ellagic acid-H] $]^{-}$ & 25,40 \\
\hline
\end{tabular}


Table 2. Estimated Thermodynamic Binding Parameters for the Interaction of Cyclic Monomeric Ellagitannins with BSA Fitted by Two-Site and One-Site Binding Models. The Values for Tellimagrandin I Have Been Previously Published. ${ }^{22} \mathrm{SD}=$ Standard Deviation Around Fit Obtained by NanoAnalyze Software; $\mathrm{n}=3$

\begin{tabular}{lrr}
\hline Two-Site & Tellimagrandin I & Tellimagrandin II \\
\hline $\mathrm{K}_{\mathrm{a} 1}\left(\mathrm{M}^{-1}\right)$ & $22188 \pm 6280$ & $8308 \pm 6248$ \\
$\Delta \mathrm{H}_{1}\left(\mathrm{~kJ} \mathrm{~mol}^{-1}\right)$ & $-20 \pm 3$ & $-33 \pm 5$ \\
$\mathrm{n}_{1}$ & $6 \pm 2$ & $29 \pm 1$ \\
$\mathrm{~K}_{\mathrm{a} 2}\left(\mathrm{M}^{-1}\right)$ & $1828 \pm 1815$ & $36 \pm 13$ \\
$\Delta \mathrm{H}_{2}\left(\mathrm{~kJ} \mathrm{~mol}^{-1}\right)$ & $-10 \pm 9$ & $-28 \pm 6$ \\
$\mathrm{n}_{2}$ & $4 \pm 1$ & $110 \pm 27$ \\
$\mathrm{SD}$ & $12 \pm 2$ & $28 \pm 6$ \\
\hline
\end{tabular}

\begin{tabular}{lrr}
\hline One-Site & Tellimagrandin I & Tellimagrandin II \\
\hline $\mathrm{K}_{\mathrm{a} 1}\left(\mathrm{M}^{-1}\right)$ & $18403 \pm 5052$ & $7284 \pm 5408$ \\
$\Delta \mathrm{H}_{1}\left(\mathrm{~kJ} \mathrm{~mol}^{-1}\right)$ & $-24 \pm 3$ & $-37 \pm 6$ \\
$\mathrm{n}_{1}$ & $6 \pm 1$ & $30 \pm 1$ \\
$\mathrm{SD}$ & $13 \pm 4$ & $25 \pm 6$ \\
\hline
\end{tabular}


Table 3. Estimated Thermodynamic Binding Parameters for the Interaction of Cyclic Dimeric and Trimeric Ellagitannins with BSA Fitted by Two-Site and One-Site Binding Models. SD = Standard Deviation Around Fit Obtained by NanoAnalyze Software; $\mathrm{n}=3$

\begin{tabular}{lrrrr}
\hline Two-Site & Agrimoniin & Gemin A & Sanguiin H-6 & Lambertianin C \\
\hline $\mathrm{K}_{\mathrm{a} 1}\left(\mathrm{M}^{-1}\right)$ & $35687 \pm 20734$ & $16413 \pm 3912$ & $35360 \pm 8262$ & $156900 \pm 16108$ \\
$\Delta \mathrm{H}_{1}\left(\mathrm{~kJ} \mathrm{~mol}^{-1}\right)$ & $-18 \pm 4$ & $-37 \pm 1$ & $-18 \pm 1$ & $-25 \pm 2$ \\
$\mathrm{n}_{1}$ & $16 \pm 1$ & $14 \pm 1$ & $17 \pm 1$ & $11 \pm 1$ \\
$\mathrm{~K}_{\mathrm{a} 2}\left(\mathrm{M}^{-1}\right)$ & $686 \pm 245$ & $784 \pm 176$ & $1134 \pm 273$ & $3117 \pm 4760$ \\
$\Delta \mathrm{H}_{2}\left(\mathrm{~kJ} \mathrm{~mol}^{-1}\right)$ & $-8 \pm 1$ & $-8 \pm 2$ & $-6 \pm 1$ & $-3 \pm 1$ \\
$\mathrm{n}_{2}$ & $46 \pm 1$ & $30 \pm 1$ & $94 \pm 12$ & $37 \pm 13$ \\
$\mathrm{SD}$ & $19 \pm 3$ & $31 \pm 3$ & $20 \pm 2$ & $20 \pm 8$ \\
\hline & & & & \\
\hline One-Site & Agrimoniin & Gemin A & Sanguiin H-6 & Lambertianin C \\
\hline $\mathrm{K}_{\mathrm{a} 1}\left(\mathrm{M}^{-1}\right)$ & $17140 \pm 5892$ & $11470 \pm 1223$ & $13337 \pm 4242$ & $107180 \pm 37045$ \\
$\Delta \mathrm{H}_{1}\left(\mathrm{~kJ} \mathrm{~mol}^{-1}\right)$ & $-24 \pm 4$ & $-45 \pm 4$ & $-26 \pm 2$ & $-28 \pm 1$ \\
$\mathrm{n}_{1}$ & $17 \pm 1$ & $14 \pm 1$ & $19 \pm 1$ & $11 \pm 1$ \\
$\mathrm{SD}$ & $20 \pm 4$ & $29 \pm 3$ & $21 \pm 3$ & $26 \pm 1$ \\
\hline
\end{tabular}


Table 4. Estimated Thermodynamic Binding Parameters for the Interaction of Cyclic Monomeric Ellagitannins with Gelatin Fitted by Two-Site and One-Site Binding Models. SD = Standard Deviation Around Fit Obtained by NanoAnalyze Software; $\mathrm{n}=3$

\begin{tabular}{lrr}
\hline Two-Site & Tellimagrandin I & Tellimagrandin II \\
\hline $\mathrm{K}_{\mathrm{a} 1}\left(\mathrm{M}^{-1}\right)$ & $175600 \pm 28614$ & $84207 \pm 16299$ \\
$\Delta \mathrm{H}_{1}\left(\mathrm{~kJ} \mathrm{~mol}^{-1}\right)$ & $-14 \pm 3$ & $-56 \pm 1$ \\
$\mathrm{n}_{1}$ & $52 \pm 19$ & $31 \pm 1$ \\
$\mathrm{~K}_{\mathrm{a} 2}\left(\mathrm{M}^{-1}\right)$ & $88693 \pm 53165$ & $7092 \pm 3005$ \\
$\Delta \mathrm{H}_{2}\left(\mathrm{~kJ} \mathrm{~mol}^{-1}\right)$ & $-11 \pm 2$ & $-3 \pm 2$ \\
$\mathrm{n}_{2}$ & $120 \pm 55$ & $59 \pm 6$ \\
$\mathrm{SD}$ & $15 \pm 2$ & $55 \pm 12$ \\
\hline
\end{tabular}

One-Site

$\mathrm{K}_{\mathrm{a} 1}\left(\mathrm{M}^{-1}\right)$

$\Delta \mathrm{H}_{1}\left(\mathrm{~kJ} \mathrm{~mol}^{-1}\right)$

$\mathrm{n}_{1}$

SD
Tellimagrandin I Tellimagrandin II

\begin{tabular}{rr}
$7592 \pm 1492$ & $76143 \pm 5888$ \\
$-39 \pm 9$ & $-59 \pm 2$ \\
$67 \pm 31$ & $31 \pm 1$ \\
$36 \pm 2$ & $48 \pm 11$ \\
\hline
\end{tabular}


Table 5. Estimated Thermodynamic Binding Parameters for the Interaction of Cyclic Dimeric and Trimeric Ellagitannins with Gelatin Fitted by Two-Site and One-Site Binding Models. SD = Standard Deviation Around Fit Obtained by NanoAnalyze Software; $\mathrm{n}=3$

\begin{tabular}{|c|c|c|c|c|c|}
\hline Two-Site & Agrimoniin & Gemin A & Sanguiin H-6 & Roshenin C & Lambertianin C \\
\hline$\Delta \mathrm{H}_{1}\left(\mathrm{~kJ} \mathrm{~mol}^{-1}\right)$ & $-65 \pm 5$ & $-64 \pm 3$ & $-63 \pm 4$ & $-30 \pm 4$ & $-91 \pm 7$ \\
\hline $\mathrm{n}_{1}$ & $18 \pm 2$ & $15 \pm 1$ & $16 \pm 1$ & $24 \pm 2$ & $11 \pm 1$ \\
\hline $\mathrm{K}_{\mathrm{a} 2}\left(\mathrm{M}^{-1}\right)$ & $11267 \pm 6161$ & $42425 \pm 11770$ & $42197 \pm 8074$ & $42063 \pm 22578$ & $250 \pm 65$ \\
\hline $\mathrm{n}_{2}$ & $52 \pm 3$ & $21 \pm 2$ & $38 \pm 2$ & $30 \pm 2$ & $15 \pm 2$ \\
\hline SD & $78 \pm 22$ & $45 \pm 18$ & $66 \pm 20$ & $57 \pm 13$ & $55 \pm 14$ \\
\hline One-Site & Agrimoniin & Gemin A & Sanguiin H-6 & Roshenin C & Lambertianin $\mathrm{C}$ \\
\hline $\mathrm{K}_{\mathrm{a} 1}\left(\mathrm{M}^{-1}\right)$ & $74353 \pm 10169$ & $417533 \pm 104665$ & $72583 \pm 14192$ & $17007 \pm 5878$ & $1534000 \pm 129526$ \\
\hline SD & $117 \pm 20$ & $88 \pm 9$ & $123 \pm 12$ & $96 \pm 16$ & $60 \pm 7$ \\
\hline
\end{tabular}


Fig. 1.

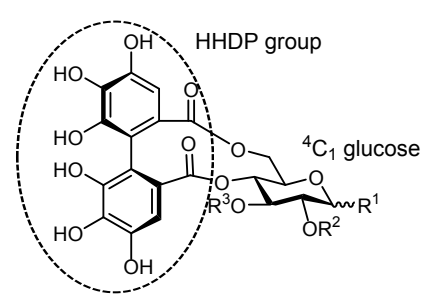

Tellimagrandin I $\mathrm{R}^{1}=\mathrm{OH}, \mathrm{R}^{2}=\mathrm{R}^{3}=\mathrm{G}$ Tellimagrandin II $\mathrm{R}^{1}=\beta-\mathrm{OG}, \mathrm{R}^{2}=\mathrm{R}^{3}=\mathrm{G}$

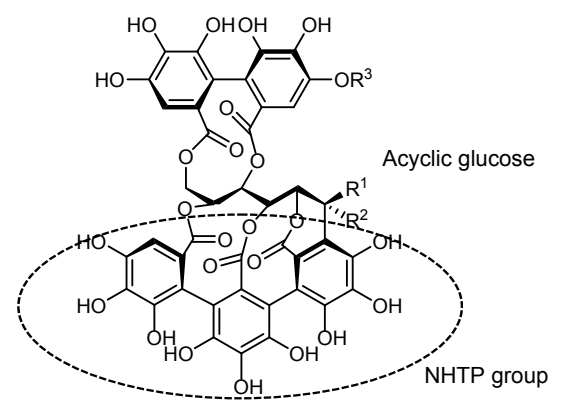

Castalagin $\mathrm{R}^{1}=\mathrm{R}^{3}=\mathrm{H}, \mathrm{R}^{2}=\mathrm{OH}$ Vescalagin $\mathrm{R}^{1}=\mathrm{OH}, \mathrm{R}^{2}=\mathrm{R}^{3}=\mathrm{H}$

Vescavaloninic acid $R^{1}=\mathrm{OH}, \mathrm{R}^{2}=\mathrm{H}, \mathrm{R}^{3}=\mathrm{A}$ Castavaloninic acid $\mathrm{R}^{1}=\mathrm{H}, \mathrm{R}^{2}=\mathrm{OH}, \mathrm{R}^{3}=\mathrm{A}$
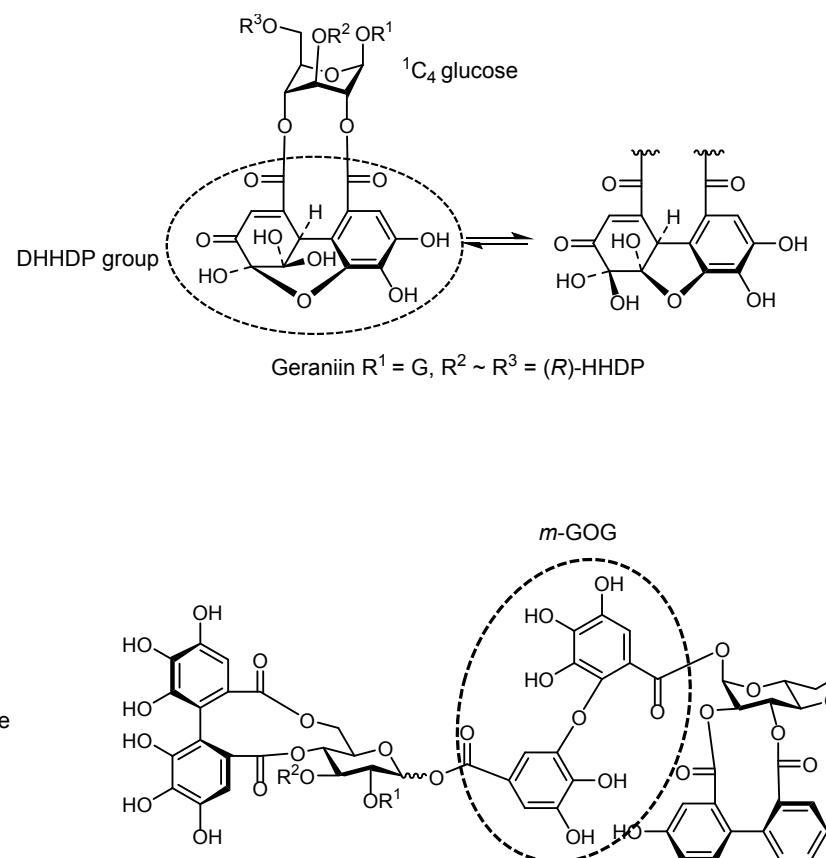

Agrimoniin $\alpha, \mathrm{R}^{1} \sim \mathrm{R}^{2}=(\mathrm{S})$-HHDP Gemin $\mathbf{A} \beta, \mathbf{R}^{1}=\mathbf{R}^{2}=\mathrm{G}$
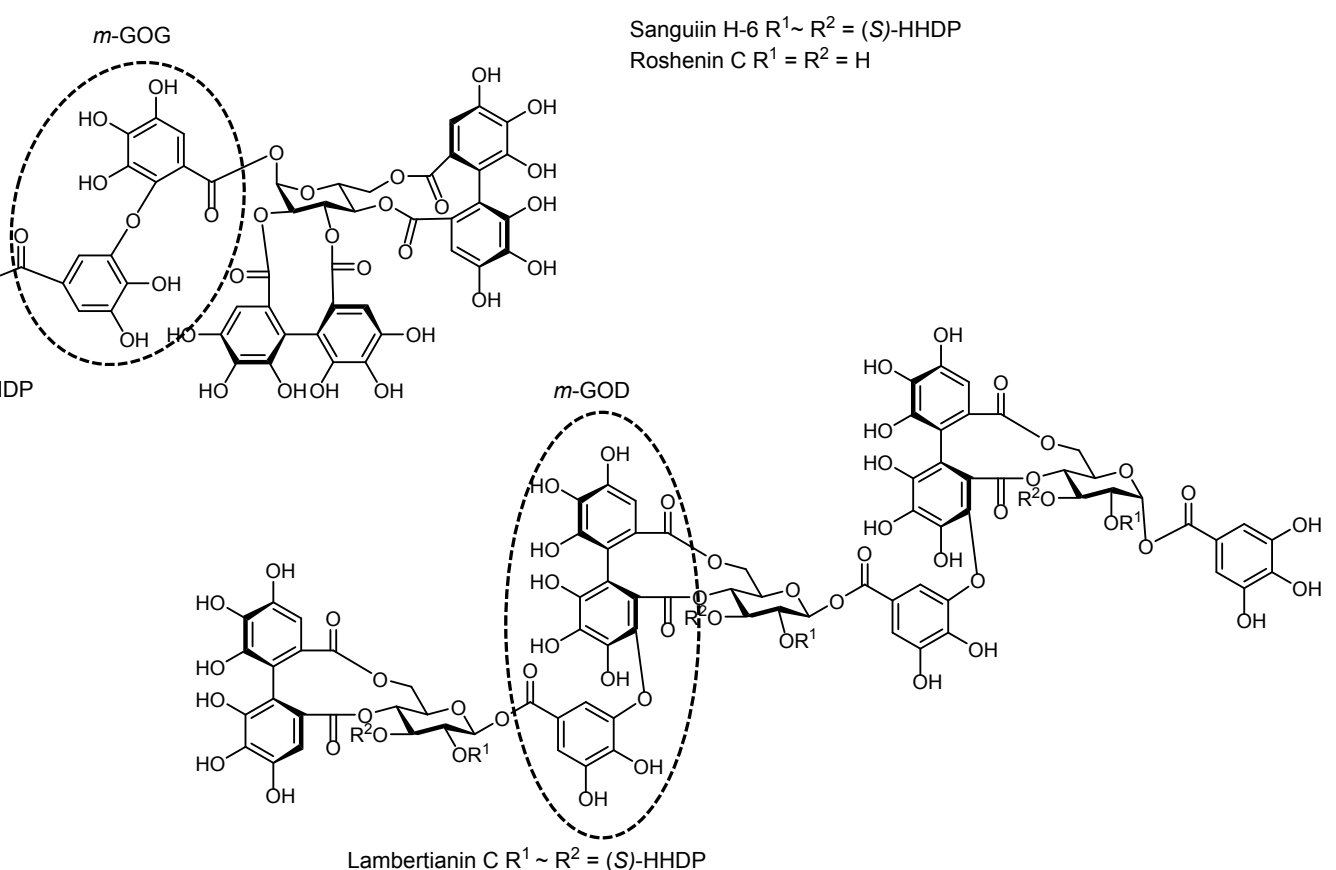

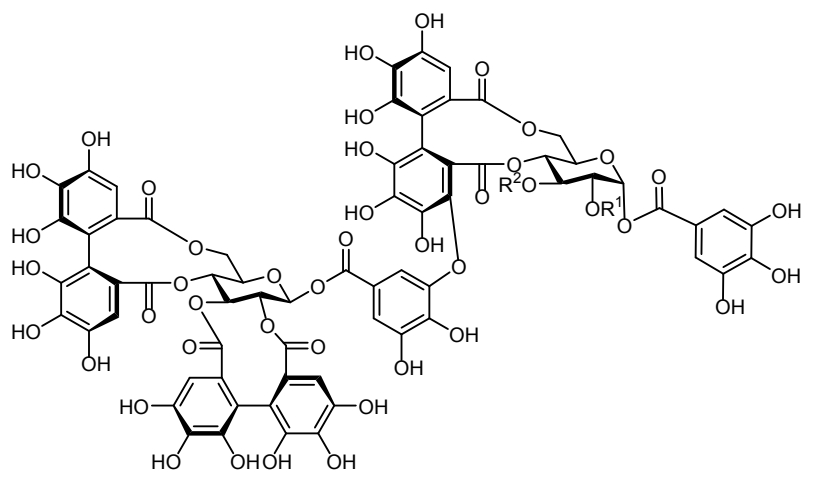

Sanguiin H-6 $\mathrm{R}^{1} \sim \mathrm{R}^{2}=(S)$-HHDP Roshenin $C \mathrm{R}^{1}=\mathrm{R}^{2}=\mathrm{H}$

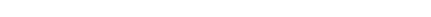


Fig. 2
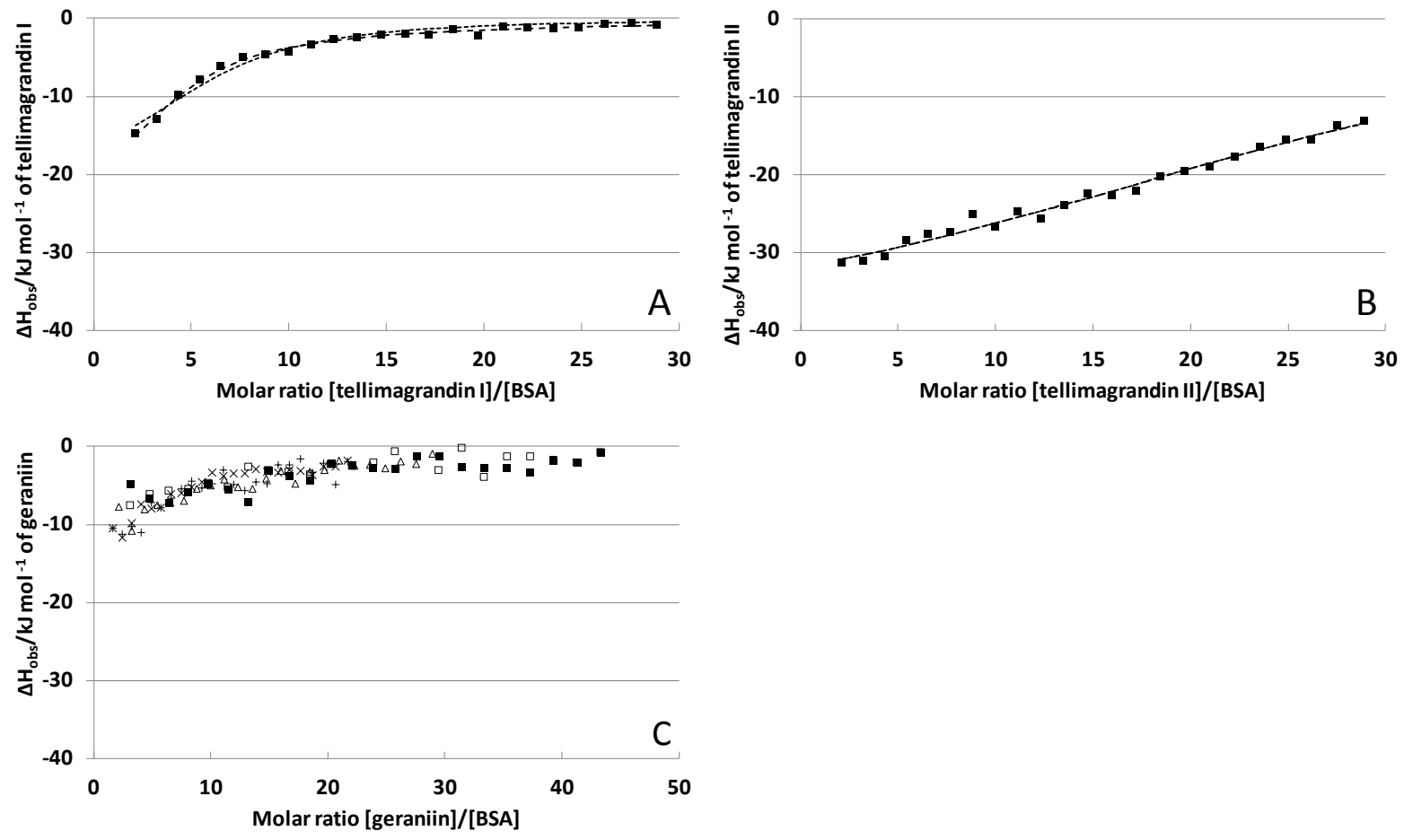
Fig. 3
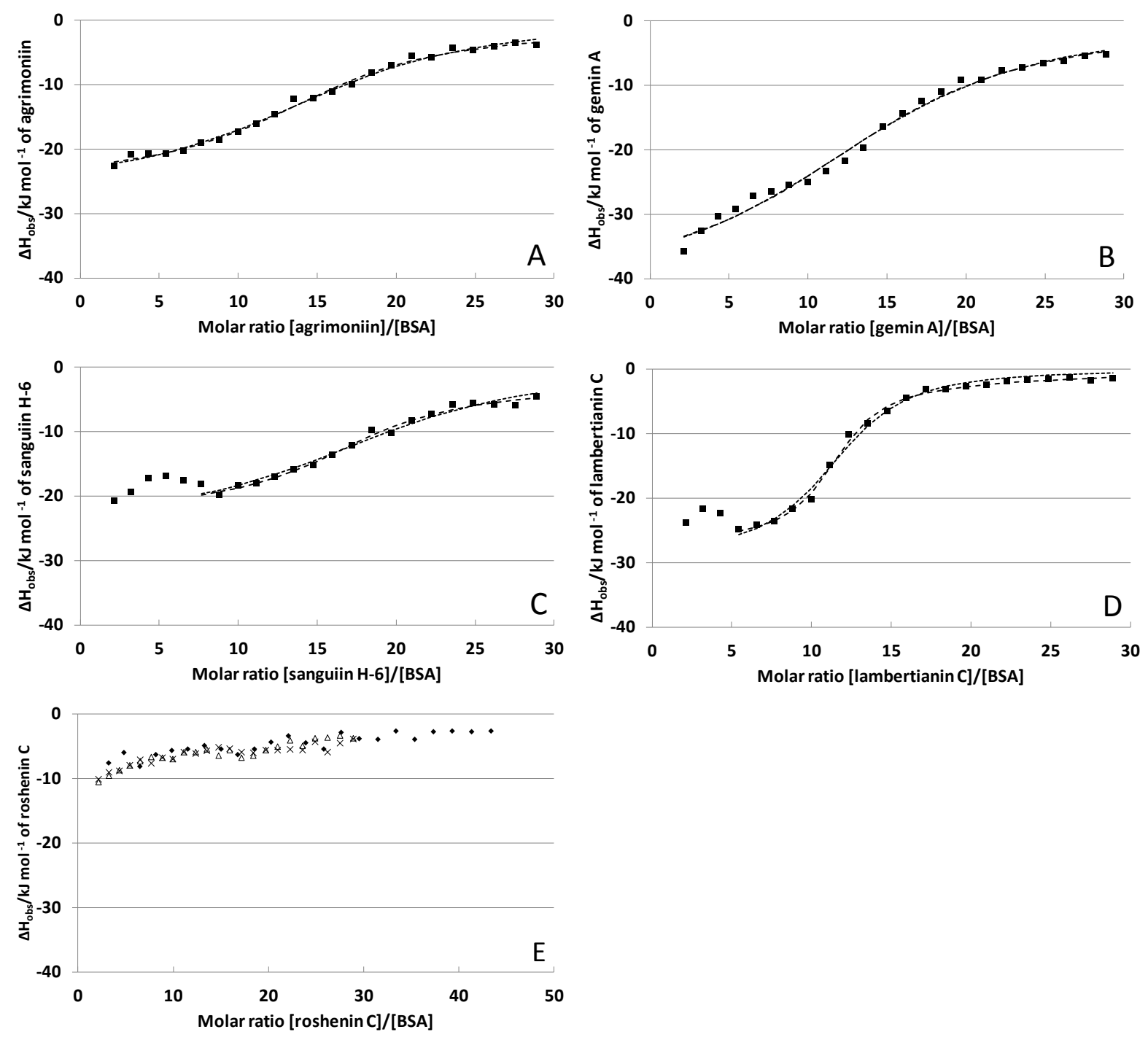
Fig. 4
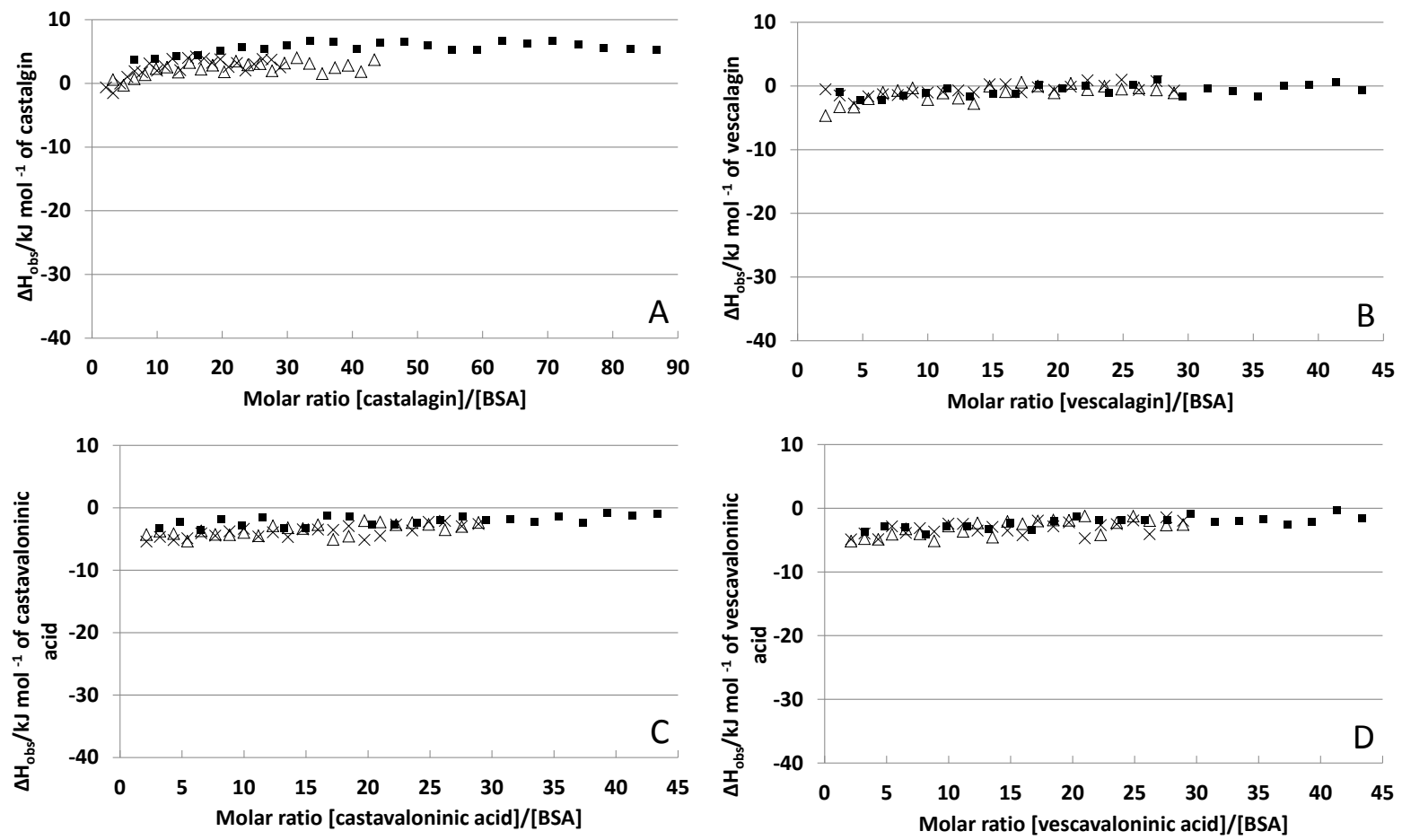
Fig. 5
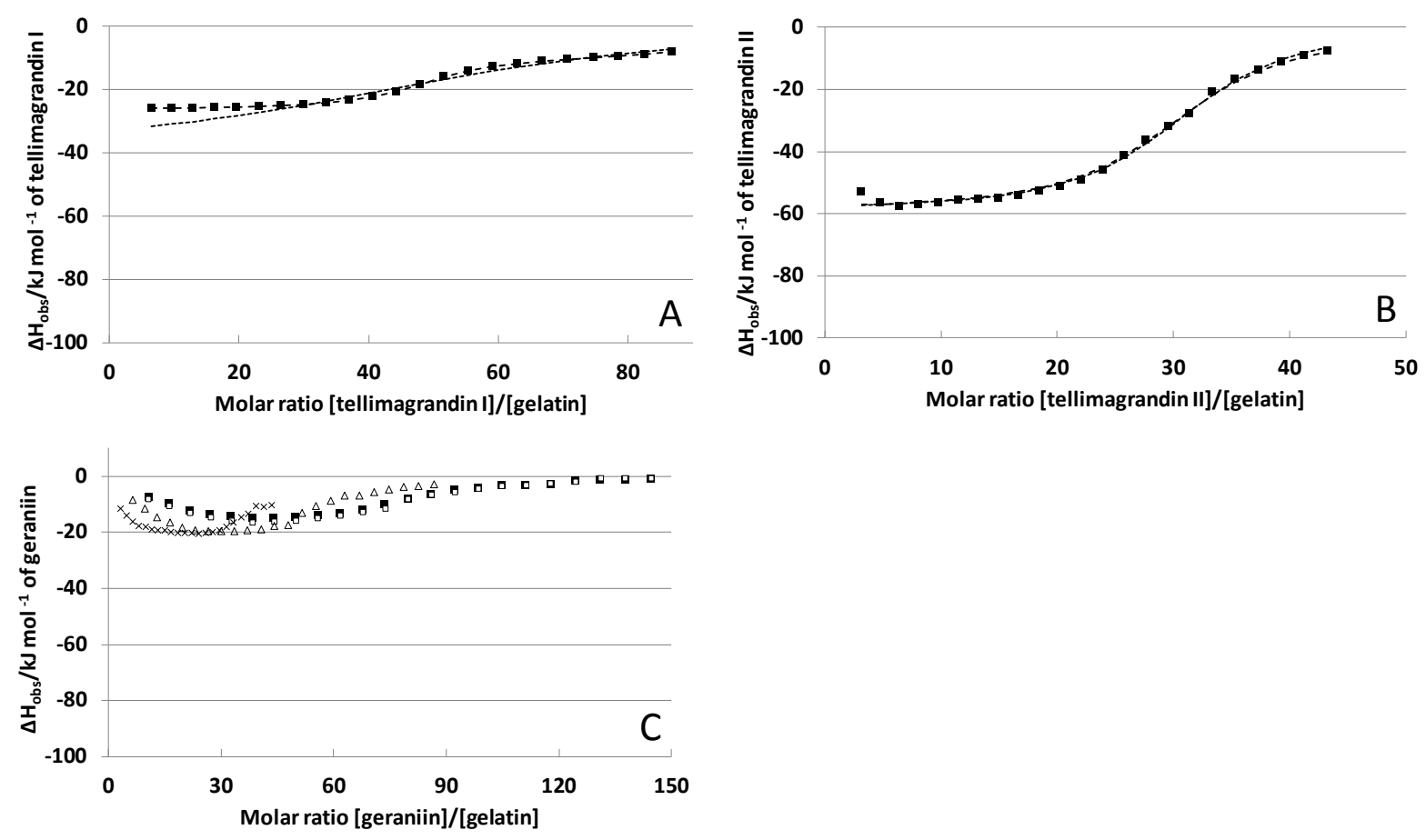
Fig. 6
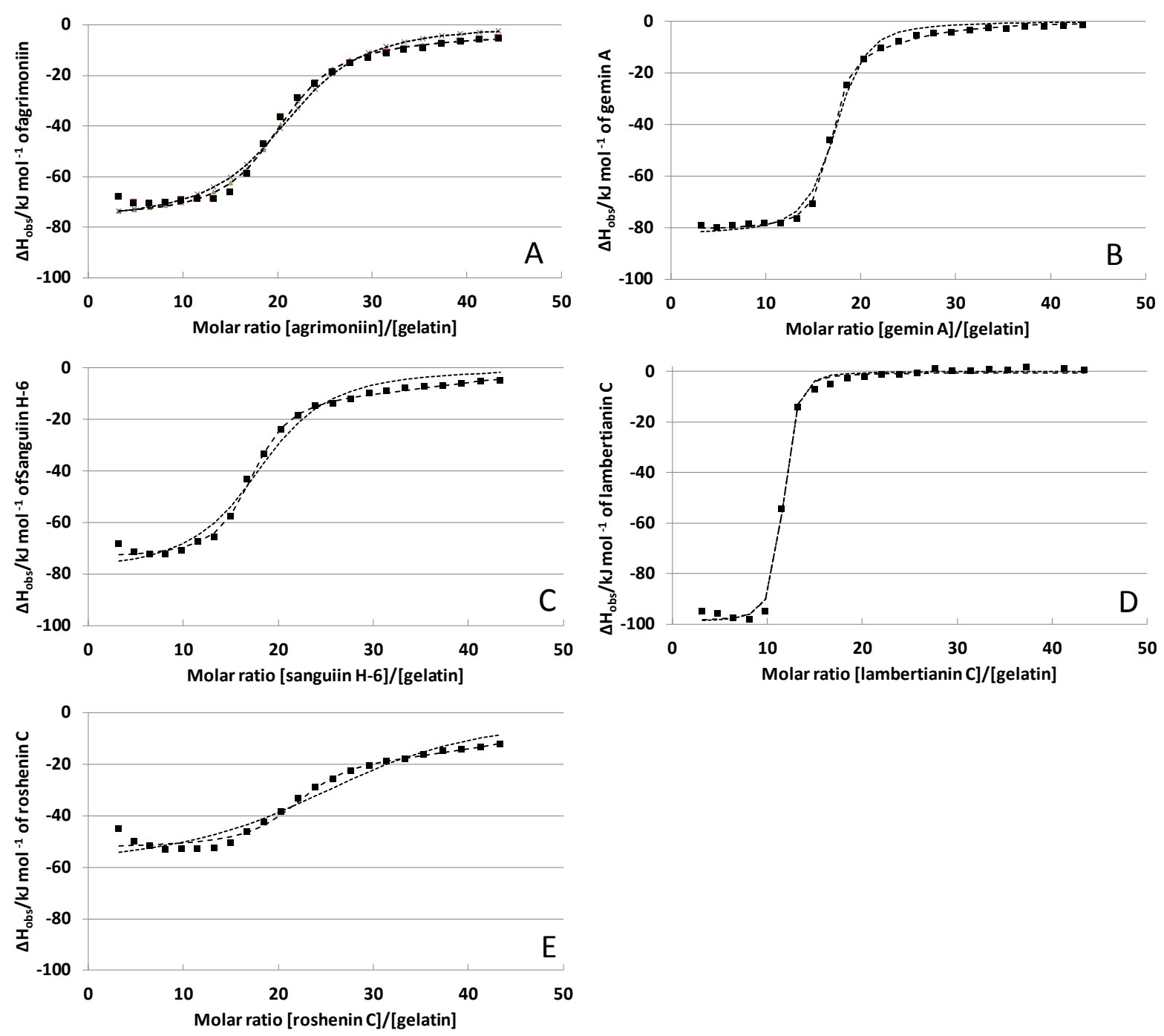
Fig. 7
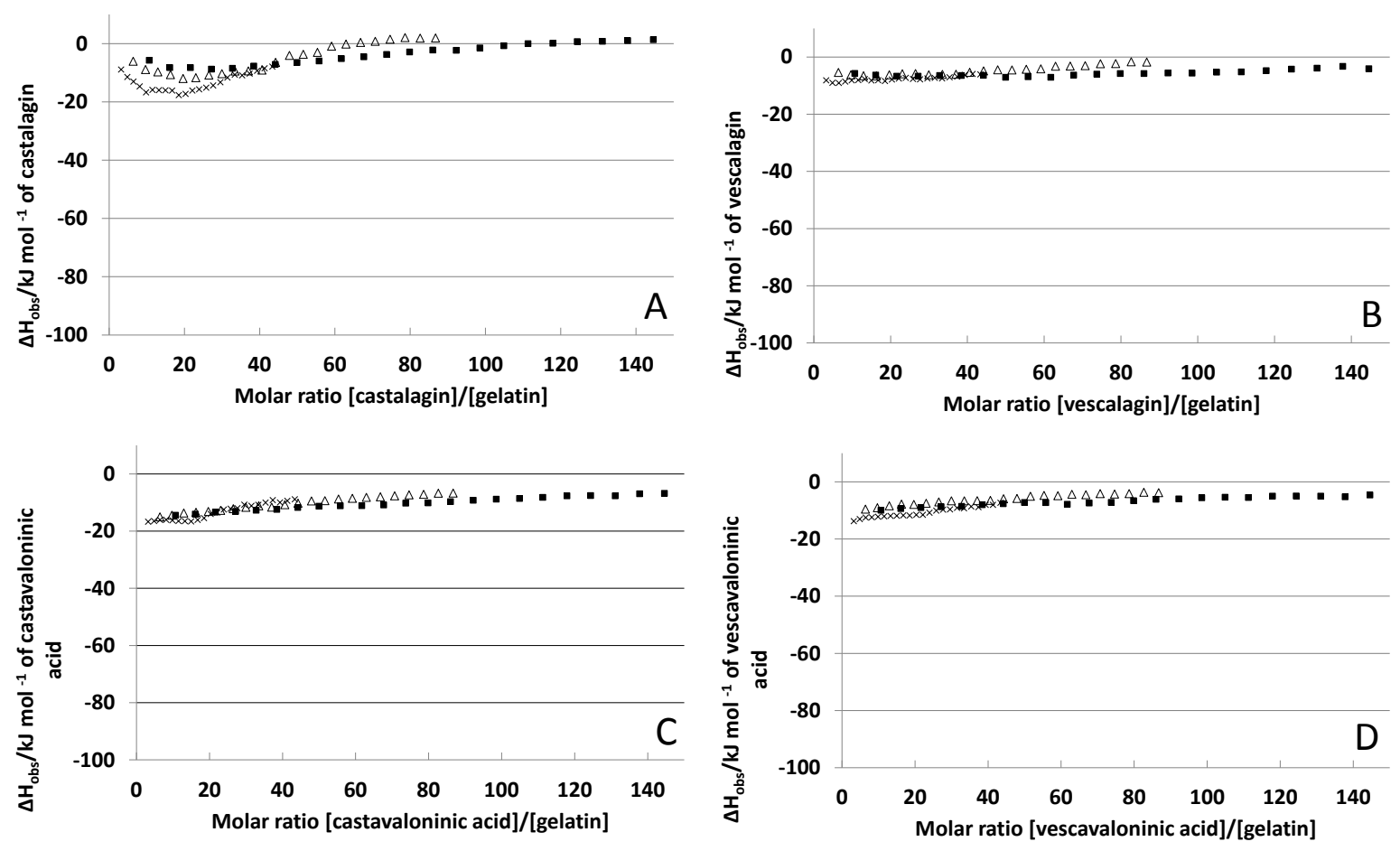
Graphic for table of contents
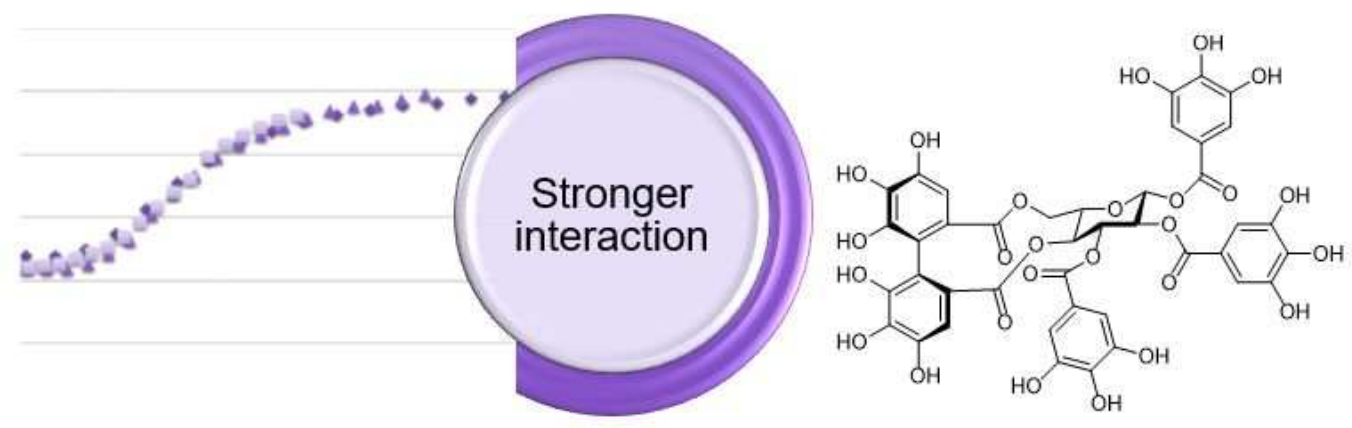

\section{Gelatin > BSA}
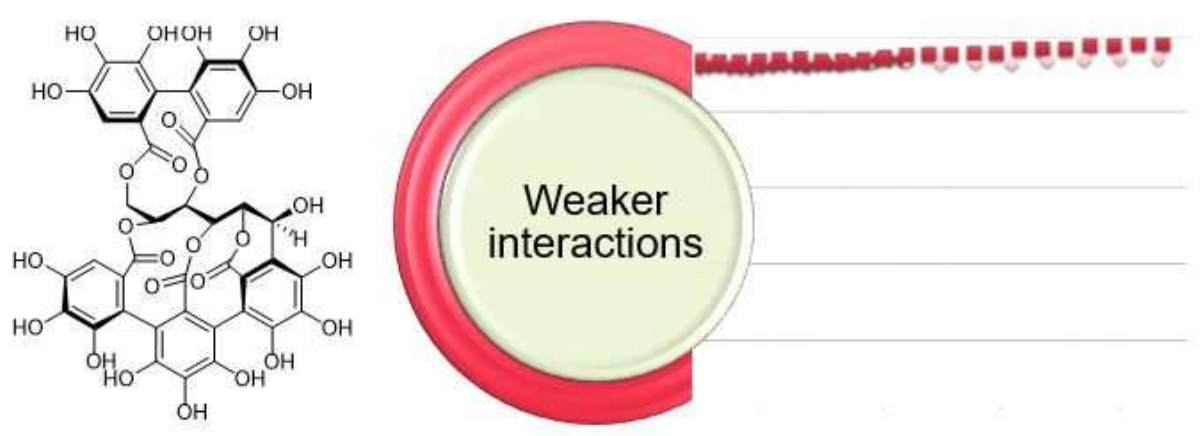